\title{
IMPROVING STUDENTS' SPEAKING SKILLS THROUGH THE APPLICATION OF EVERY ONE IS A TEACHER HERE LEARNING STRATEGY
}

\author{
Asriadi \\ SD Negeri 020 Karya Tani Kecamatan Kempas, Indonesia \\ asriadi.kps75@gmail.com
}

\begin{abstract}
This research was motivated by the students' low ability in communication. Considering the small number of students, it seemed appropriate to apply Everyone is a Teacher Here learning strategy so that students became active in learning process, especially in speaking. This research was a classroom action research conducted to sixth grade students at SDN 020 Karya Tani, Kecamatan Kempas. There were 7 students consisting of 2 male students and 5 female students. The instruments used in this research were observation sheets and the speaking ability. The results showed that the average score of the students' speaking ability in cycle I was $69.71 \%$ which was in the medium category. Then, in the second cycle, it increased to $82.85 \%$ which was in the high category. Based on the research results, it was concluded that Everyone is a Teacher Here learning strategy improved students' speaking skills.
\end{abstract}

Keywords: speaking skills, everyone is a teacher here

\section{UPAYA MENINGKATKAN KETERAMPILAN BERBICARA SISWA MELALUI PENERAPAN STRATEGI PEMBELAJARAN EVERY ONE IS A TEACHER HERE}

\begin{abstract}
ABSTRAK
Penelitian ini dilatarbelakangi oleh rendahnya kemampuan siswa dalam berkomunikasi. Menimbang jumlah siswa yang sedikit maka dirasa tepat menerapkan strategi pembelajaran everyone is a teacher here agar siswa aktif dalam belajar terutama dalam hal kemampuan berbicara. Penelitian ini merupakan penelitian tindakan kelas yang dilakukan pada siswa kelas VI SDN 020 Karya Tani Kecamatan Kempas. Jumlah siswa adalah sebanyak 7 orang dengan laki-laki berjumlah 2 siswa dan perempuan berjumlah 5 siswa. Instrumen yang digunakan adalah lembar observasi keterlaksanaan kegiatan pembelajaran dan tes kemampuan berbicara siswa. Hasil penelitian menunjukkan kemampuan berbicara siswa pada siklus I memiliki rata-rata sebesar $69.71 \%$ yang merupakan kategori sedang. Pada siklus II mengalami peningkatan menjadi $82.85 \%$ yang masuk kategori tinggi. Kesimpulan berdasarkan hasil penelitian adalah penerapan strategi pembelajaran everyone is a teacher here dapat meningkatkan kemampuan berbicara siswa.
\end{abstract}

Kata Kunci: keterampilan berbicara, everyone is a teacher here

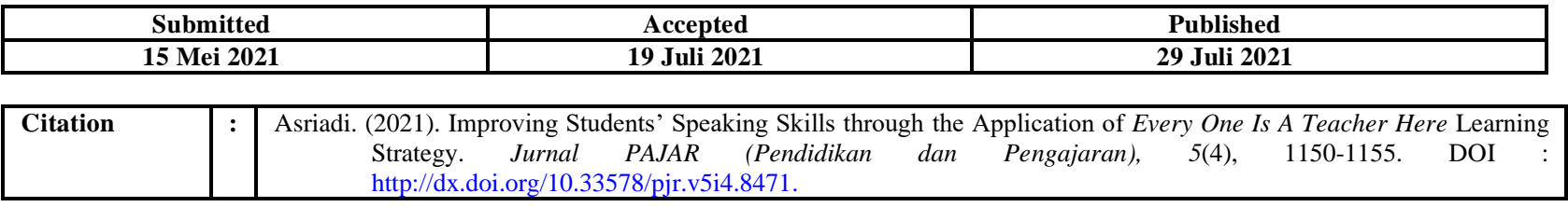

\section{PENDAHULUAN}

Untuk menghasilkan manusia yang cerdas serta mampu bersaing di era globalisasi diperlukan pedidikan yang berkualitas karena berperan dalam membentuk karakter, perkembangan ilmu dan mental seseorang dalam tahap tumbuh kembang yang pada masa mendatang menjadi seorang yang melakukan interaksi dan aktivitas dalam lingkungan sesuai dengan kemampuan masingmasing.

Harapan tersebut menuntut pendidikan terutama ujung tombak yakni guru untuk lebih siap dalam menyiapkan generasi bangsa dengan berbagai upaya seperti menganalisis kebutuhan siswa, menyiapkan dan melaksanakan kegiatan pembelajaran yang dapat memfasilitasi pemenuhan kebutuhan siswa, dan mengevaluasi pencapaian yang dipenuhi oleh siswa sebagai tolak ukur keberhasilan terhadap tindakan yang dilakukan guru.

Salah satu kemampuan yang diharapkan dapat dikuasai oleh siswa di abad 21 adalah kemampuan berkomunikasi. Melalui komunikasi siswa siswa dapat menggunakan informasi, berbagi, dan menggunakannya untuk memecahkan masalah yang kompleks. Ketidak mampuan siswa untuk mengungkapkan keinginan, perasaan serta 
mengaktualisasikan yang ada dalam dirinya dapat menimbulkan masalah (Frasandy, 2018).

Namun fakta di lapangan yang dilakukan pada Senin tanggal 3 februari 2020 ditemukan bahwa kemampuan siswa dalam berkomunikasi masih rendah. Kegiatan pembelajaran tidak menuntut siswa untuk aktif dalam pembelajaran sehingga siswa malu bahkan tidak mau untuk bertanya. Pada saat diberikan pertanyaan oleh guru maka sangat sulit mendapatkan jawaban yang lengkap disertai dengan penjelasan yang dapat memberikan pemahaman terhadap penanya maupun siswa lain yang mendengarkan. Dalam hal kefasihan dalam berkomunikasi masih kurang baik dan juga artikulasinya masih menimbulkan makna yang ganda sehingga dapat terjadinya miskomunikasi antara pembicara dengan pendengar. Hal ini juga diperkuat dengan hasil tes awal kemampuan komunikasi siswa yang masih rendah dimana dari 7 siswa hanya 1 (14.28\%) siswa yang mampu menunjukkan kecakapan dalam berkomunikasi.

Melihat kondisi tersebut, maka peneliti bermaksud melakukan tindakan penelitian untuk dapat meningkatkan kemampuan berkomunikasi siswa. Salahsatu strategi yang dianggap tepat dan telah dibuktikan oleh penelitian lain (Nurmalasari, 2019) adalah strategi pembelajaran Everyone is Teacher Here. Strategi ini memberikan kesempatan bagi setiap siswa untuk aktif berperan seolah menjadi guru bagi siswa lainnya (Silberman, 2009). Strategi ini juga dipilih karena alasan jumlah siswa yang sedikit sehingga setiap siswa dapat diberikan tugas dan peran sebagai guru bagi siswa lainnya.

Penelitian ini bertujuan agar siswa menjadi aktif dalam belajar terutama dalam hal berbicara menjadi lebih terampil. Siswa diminta berperan seolah olah menjadi seorang guru yang diberikan kesempatan untuk memberikan penjelasan kepada teman-teman kelasnya terkait materi yang sedang dipelajari. Oleh karena itu pembelajaran everyone is a teacher here dirasa sangat tepat untuk meningkatkan kemampuan siswa dalam berbicara.

\section{KAJIAN TEORETIS Keterampilan Berbicara}

Komunikasi merupakan proses pertukaran bahasa yang berlangsung antara manusia satu dengan lainnya baik dalam konteks intrapersonal, kelompok, maupun massa. Bahasa diakui sebagai media yang paling efektif dalam melakukan komunikasi pada suatu interaksi antar individu seperti halnya kegiatan penyuluhan dan pembinaan, proses belajar mengajar, pertemuan tempat kerja dan lain-lain (Muhtadi, 2012).

Salah satu kemampuan berkomunikasi adalah kemampuan berbicara. Menurut Mark (dalam Susanti, 2017) kemampuan berbicara adalah tindakan untuk menghasilkan ujaran yang bertujuan untuk mengungkapkan pendapat, ide-ide atau keinginan dalam rangka mempertahankan hubungan sosial atau sekedar menyampaikan informasi.

Adapun indikator keterampilan berbicara siswa adalah sebagai berikut (Padmawati, 2019):

Tabel 1. Indikator Keterampilan Berbicara

\begin{tabular}{rll}
\hline No. & \multicolumn{1}{c}{ Aspek Penilaian } & \multicolumn{1}{c}{ Deskripsi } \\
\hline 1. & Lafal & Siswa menyampaikan informasi dengan lafal yang jelas \\
2. & Intonasi & Siswa menyampaikan informasi dengan intonasi yang \\
tepat & Kelancaran & Siswa lancar dalam menyampaikan informasi \\
4. & Ekspresi & $\begin{array}{l}\text { Siswa menggunakan ekspresi dalam menyampaikan } \\
\text { informasi }\end{array}$ \\
5. & $\begin{array}{l}\text { Ketepatan } \\
\text { pembicaraan }\end{array}$ & Siswa menyampaikan isi pembicaraan dengan kalimat \\
\end{tabular}




\section{Everyone is A Teacher Here}

Strategi pembelajaran everyone is teacher here dapat diartikan sebagai setiap siswa adalah guru. Hal ini bertujuan agar seluruh siswa terlibat aktif dalam kegiatan pembelajaran dan berperan seperti seorang guru bagi siswa lainnya. Strategi ini dapat membuat proses pembelajaran lebih aktif dan mengembangkan kemampuan berpikir siswa (Aryaningrum, 2015).

Langkah-langkah strategi pembelajaran Everyone is A Teacher Here menurut Djamarah (2010) adalah sebagai berikut: 1) bagikan secarik kertas / kartu indeks kepada seluruh siswa dan minta mereka menuliskan satu pertanyaan tentang materi pelajaran atau topik khusus yang sedang dipelajari di kelas; 2) kumpulkan kertas lalu acak dan bagikan pada siswa, pastikan bahwa tidak ada siswa yang menerima soal yang ditulis sendiri. Minta mereka membaca dalam hati kemudian memikirkan jawabannya; 3) minta siswa secara bergiliran untuk membacakan pertanyaan dan memberikan jawaban dan penjelasan terkait pertanyaan yang diperoleh; 4) setelah siswa memberikan penjelasan, mintalah siswa lain memberikan tanggapan untuk menambahkan penjelasan; 5) lanjutkan sampai seluruh siswa mendapat kesempatan yang sama.

\section{METODE PENELITIAN}

Penelitian ini dirancang dengan menggunakan metode Penelitian Tindakan Kelas yang memiliki tahapan perencanaan, pelaksanaan, pengamatan, dan refleksi. Penelitian ini bertujuan agar kemampuan siswa terutama dalam hal berbicara dapat mengalami peningkatan dengan diterapkannya strategi pembelajaran everyone is a teacher here.

Pelaksanaan penelitian ini berlokasi di SDN 020 Karya Tani Kecamatan Kempas dengan subjek penelitian adalah siswa kelas VI yang berjumlah 7 orang dengan laki-laki 2 dan perempuan 5 orang. Jadwal penelitian ini dimulai bulan februari sampai maret 2020. Data bersumber dari observasi kegiatan siswa berdasarkan indikator pembelajaran dengan menggunakan strategi pembelajaran everyone is a teacher here dan kemampuan berbicara siswa. Instumen yang digunakan adalah lembar observasi kegiatan siswa dan tes kemampuan berbicara. Adapun analisis data menggunakan rumus berikut (Nurmalasari, 2019):

$$
P=\frac{F}{N} \times 100 \%
$$

Keterangan:

$\mathrm{P}=$ Persentase kegiatan siswa

$\mathrm{F}$ = banyaknya kegiatan siswa yang muncul

$\mathrm{N}=$ jumlah kegiatan siswa keseluruhan

Setelah diperoleh persentase rata-rata kegiatan siswa, maka selanjutnya dikategorikan ke dalam klasifikasi berikut (Purwanto dalam Nurmalasari, 2019):

Tabel 2. Kategori Keterlaksanaan Kegiatan Pembelajaran

\begin{tabular}{ccc}
\hline No. & $\begin{array}{c}\text { Persentase } \\
\text { Keterlaksanaan }\end{array}$ & Kategori \\
\hline 1. & $0-19$ & Tidak aktif \\
2. & $20-39$ & Kurang aktif \\
3. & $40-59$ & Cukup \\
4. & $60-79$ & Aktif \\
5. & $80-100$ & Sangat aktif \\
\hline
\end{tabular}

Untuk mencari kemampuan berbicara menggunakan rumus berikut:

Nilai akhir $=\frac{\text { skor yang diperoleh }}{\text { skor maksimal }} \times 100 \%$
Setelah diperoleh hasil kemampuan berbicara siswa maka diklasifikasikan dalam kategori berikut (Padmawati, 2019): 
Jurnal PAJAR (Pendidikan dan Pengajaran)

Volume 5 Nomor 3 April 2021 | ISSN Cetak : 2580 - 8435| ISSN Online : 2614 - 1337

DOI : http://dx.doi.org/10.33578/pjr.v5i4.8471

Tabel 3. Kategori Kemampuan Berbicara Siswa

\begin{tabular}{ccc}
\hline No. & $\begin{array}{c}\text { Persentase Kemampuan } \\
\text { Berbicara Siswa }\end{array}$ & Kategori \\
\hline 1. & $90-100$ & Sangat Tinggi \\
2. & $80-89$ & Tinggi \\
3. & $65-79$ & Sedang \\
4. & $55-64$ & Rendah \\
5. & $0-54$ & Sangat Rendah \\
\hline
\end{tabular}

Indikator keberhasilan penelitian ini adalah jika kegiatan siswa mencapai persentase rata-rata sebesar $\geq 80 \%$ dengan kategori sangat aktif dan kemampuan berbicara siswa sebesar $\geq 80$ dengan kategori tinggi.

\section{HASIL DAN PEMBAHASAN \\ Hasil \\ Kegiatan Pembelajaran Siswa}

Kegiatan pembelajaran berjalan dengan baik. Keterlaksanaan kegiatan pembelajaran siswa dalam penerapan pembelajaran everyone is a teacher here dihasilkan nilai perhitungan sebagai berikut:

Persentase kegiatan siswa pada siklus I:

$$
\begin{gathered}
=\frac{18}{25} \times 100 \% \\
=72 \%
\end{gathered}
$$

Persentase kegiatan siswa pada siklus II:

$$
\begin{gathered}
=\frac{22}{25} \times 100 \% \\
=88 \%
\end{gathered}
$$

\section{Kemampuan Berbicara Siswa}

Kemampuan berbicara siswa setelah diberikan tindakan berupa pembelajaran everyone is a teacher here mengalami peningkatan. Siswa menjadi senang dan aktif dalam mengikuti kegiatan pembelajaran yang disajikan guru karena setiap siswa diberikan kesempatan untuk berperan sebagai guru sehingga siswa dapat memberikan penjelasan terkait pembelajaran seolah-olah dia adalah guru yang memberikan pengajaran di kelas. Adapun kemampuan siswa pada siklus I dan II

\begin{tabular}{|c|c|c|}
\hline \multirow{2}{*}{ Indikator Kemampuan Berbicara } & \multicolumn{2}{|c|}{ Persentase Rata-rata (\%) } \\
\hline & Siklus I & Siklus II \\
\hline Lafal & $74.28 \%$ & $85.71 \%$ \\
\hline Intonasi & $71.42 \%$ & $82.85 \%$ \\
\hline Kelancaran & $68.57 \%$ & $82.85 \%$ \\
\hline Ekspresi & $68.57 \%$ & $85.71 \%$ \\
\hline Ketepatan Isi Pembicaraan & $65.71 \%$ & $77.15 \%$ \\
\hline Rata-rata & $69.71 \%$ & $82.85 \%$ \\
\hline Kategori & Sedang & Tinggi \\
\hline
\end{tabular}
secara lebih rinci masing-masing disajikan pada tabel 4 berikut ini:

Tabel 4. Rekapitulasi Kemampuan Berbicara Siswa pada Siklus I dan I

Berdasarkan hasil pengamatan serta melihat persentase rata-rata kemampuan berbicara siswa dari setiap siklusnya mengalami peningkatan. Pada siklus I, kemampuan berbicara siswa memiliki rata-rata sebesar $69.71 \%$, hasil ini merupakan kategori sedang yang berarti kemampuan siswa dalam berbicara cukup baik.
Pada siklus II kemampuan siswa mencapai nilai yang diharapkan yakni $82.85 \%$ dengan masuk dalam kategori tinggi. 


\section{Pembahasan}

\section{Kegiatan Pembelajaran Siswa}

Pada siklus I keterlaksanaan kegiatan pembelajaran siswa sebesar $72 \%$ dimana nilai ini termasuk dalam kategori aktif. Terlihat dari kegiatan siswa yang bersemangat mengikuti kegiatan pembelajaran, hanya saja siswa masih terlihat malu dan agak sulit untuk diminta maju ke depan untuk menjelaskan persoalan yang dibahas. Siswa hanya berani memberikan penjelasan di bangku masing-masing dengan mengandalkan penjelasan yang terdapat di dalam buku tanpa memberikan pemahaman yang luas baik dari informasi lain maunpun pengalaman yang mereka temukan di luar sekolah. Menurut Marhayati (2018) pembelajaran everyone is a teacher here dapat meningkatkan pemahaman konsep dan kemampuan komunikasi siswa. Di lain sisi, pemahaman siswa dapat diperoleh melalui serangkaian kegiatan pembelajaran bersama dengan orang lain sehingga membentuk pengetahuan dan pemahaman dari pengalaman belajarnya (Siagian, 2017).

Pada siklus II, siswa sangat antusias dalam mengikuti pembelajaran yang disajikan guru serta berupaya menunjukkan kemampuan terbaik agar mendapat penilaian terbaik dari guru. Siswa mulai percaya diri (Firdaus, 2018) dan berani maju ke depan kelas serta memberikan penjelasan yang menarik seperti menggunakan papan tulis untuk menggambarkan materi yang dipelajari atau memanfaatkan benda-benda yang ada di dalam kelas. Hal ini semacam ini juga dibuktikan dari penelitian Ashifa (2019).

Pembelajaran everyone is a teacher here ini dapat meningkatkan partisipasi siswa yang besar serta menimbulkan rasa tanggung jawab dari diri siswa (Hendra, 2013). Aktivitas siswa yang tinggi merupakan peran dari model pembelajaran ETH yang diterapkan karena setiap siswa diminta untuk melakukan perannya masing-masing sebagai guru bagi siswa lain sesuai dengan soal yang didapatkan dari kertas yang ditulis oleh siswa (Zuliani, 2017). Siswa berupaya untuk dapat mencaritahu jawaban dari pertanyaan yang ada di dalam kertas yang ia terima agar dapat memberikan penjelasan dan pemahaman terhadap siswa lainnya.

\section{Kemampuan Berbicara Siswa}

Pada siklus I, siswa mampu melafalkan kata dan kaliat dengan jelas dan intonasi yang tepat sehingga penguatan penjelasan siswa yang menjadi guru dapat dipahami dengan baik. Terkait dengan kelancaran dan ekspresi memiliki nilai yang sama, hal ini juga menggambarkan bahwa siswa tidak terbata-bata dalam memberikan penjelasan pada siswa lain dan menunjukkan ekpresi yang bersemangat dan menyenangkan siswa lainnya. Sementara pada indikator ketepatan isi yang merupakan nilai rata-rata terendah perlu diasah lebih dalam agar pengetahuan siswa lebih luas dan tidak terbatas pada satu sumber saja. Hal ini dilakukan agar siswa dapat memberikan penjelasan yang lebih terperinci terhadap suatu materi yang dipertanyakan. Siswa menjadi terbiasa dan dapat melatih dirinya untuk menyampaikan pengetahuan yang dimiikinya (Astiar, 2020).

Pada siklus II, lafal yang diucapkan terdengar dengan jelas sehingga tidak terjadi salah arti bagi yang mendengarkannya, intonasi sangat bagus dengan memberikan penekanan terhadap suatu kalimat yang mungkin saja dapat menimbulkan kebingungan jika tidak dijelaskan. Siswa juga tidak ragu dan terbata-bata dalam memberikan penjelasan secara gamblang dan diiringi dengan ekspresi yang penuh semangat. Isi pembicaraan juga sudah lebih baik daripada siklus sebelumnya. Hal ini membuktikan bahwa melalui pembelajaran everyone is a teacher here dapat meningkatkan kemampuan siswa dalam berbicara, senada dengan yang dibuktikan melalui penelitian Monika (2020).

\section{SIMPULAN DAN REKOMENDASI}

Berdasarkan hasil penelitian dan pembahasan yang telah diuraikan di atas dapat ditarik kesimpulan bahwa penerapan strategi pembelajaran everyone is a teacher here dapat meningkatkan kemampuan berbicara siswa kelas VI SDN 020 Karya Tani Kecamatan Kempas Kabupaten Indragiri Hulu.

Rekomendasi yang diajukan bagi penelitian selanjutnya adalah guru lebih menyiapkan siswa dengan berbagai macam sumber bahan ajar supaya pengetahuan siswa lebih luas dan memudahkan siswa dalam memberikan 
penjelasan yang dapat menguatkan pemahaman siswa yang baik secara menyeluruh

\section{DAFTAR PUSTAKA}

Aryaningrum, K. (2015). Pengaruh Strategi Pembelajaran Everyone is A Teacher Here Terhadap Hasil Belajar Siswa pada Mata Pelajaran IPS Terpadu (Geografi) di Kelas VIII SMP Negeri 1 Belitang III OKU Timur. Jurnal Ilmiah CIVIS, 5 (2), 798807.

Ashifa, D, D., Effendi, L, A., dan Sthephani, A. (2019). Pengaruh Strategi Belajar Aktif Tipe Everyone is A Teacher Here (ETH) Terhadap Hasil Belajar Matematika Siswa SMA. AKSIOMATIK, 7 (3), 25-33.

Astiar, F, A., Satianingsih, R., dan Yustitia, V. (2020). Students Speaking Skills Through Project Based Learning at Elementary Schools. PRIMARY: Jurnal Pendidikan Guru Sekolah Dasar, 9 (5), 672-679.

Firdaus, A, R. (2018). Application of Everyone is A Teacher Here Learning Model to Improve Self Convidence Students. Journal of Elementary Education, 2 (2), 87-95.

Hendra, I, K., Meter, I, G., dan Negara, O. (2013). Pengaruh Strategi Pembelajaran Aktif Tipe Everyone is A Teacher Here Terhadap Hasil Belajar IPA Kelas IV SDN 2 Dangin Puri. Mimbar PGSD Undhiksa, 1 (1), 1-12.

Marhayati, L. (2018). Pengaruh Strategi Everyone is A Teacher Here Terhadap Pemahaman Konsep dan Kemampuan Komunikasi Matematis Siswa SMA SPP Dr. M. Natsir Alahan Panjang. Journal of RESIDU, 2 (6), 50-57.

Monika, M., Simarmata, M, Y., dan Hartati, M. (2020). Peningkatan Keterampilan Berbicara dalam Pidato Persuasif dengan Strategi Pembelajaran Everyone is A Teacher Here pada Siswa Kelas IX A SMP Negeri 1 Sekadau Hulu. EduIndo: Jurnal Pendidikan Bahasa Indonesia dan Sastra Indonesia, 1 (1), 1-12.

Muhtadi, A, S. (2012). Komunikasi Dakwah Teori Pendekatan dan Aplikasinya. Bandung: Simbiosa Rekatama Media.
Nurmalasari, L. (2019). Penerapan Strategi Pembelajaran Everyone is Teacher Here untuk Meningkatkan Keterampilan Berbicara Siswa. Al-Aulad: Journal of Islamic Primary Education, 9 (1), 93-106.

Padmawati, K, D., Arini, N, W., dan Yudiana, K. (2019). Analisis Keterampilan Berbicara Siswa Kelas V Mata Pelajaran Bahasa Indonesia. Journal for Lesson and Learning Studies, 2 (2), 190-200.

Septikasari, R., dan Frasandy, R, N. (2018). Keterampilan 4C Abad 21 dalam Pembelajaran Pendidikan Dasar. Jurnal Tarbiyah Al-Awlad, 8 (2), 112-122.

Siagian, M, D. (2017). Pembelajaran Matematika dalam Perspektif Konstruktivisme. NIZHAMIYAH (Jurnal Pendidikan Islam dan Teknologi Pendidikan), 7 (2), 61-73.

Silberman, M. (2004). Active Learning, 101 Strategi Pembelajaran Aktif, (terjemahan Sarjuli et al). Yogyakarta: YAPPENDIS.

Susanti, Y, O. (2017). Meningkatkan Kemampuan Berbicara Anak Melalui Bermain Peran Mikro. Jurnal Potensia, PG-PAUD FKIP UNIB, 2 (1), 63-70.

Zuliani, P., dan Nasir, M. (2017). Penerapan Model Pembelajaran Everyone is A Teacher Here (ETH) untuk Meningkatkan Aktivitas dan Hasil Belajar Kimia Koloid Siswa Kelas XI 1A di SMA Negeri 5 Banda Aceh. Jurnal Ilmiah Mahasiswa Pendidikan Kimia (JIMPK), 2 (1), 65-72. 